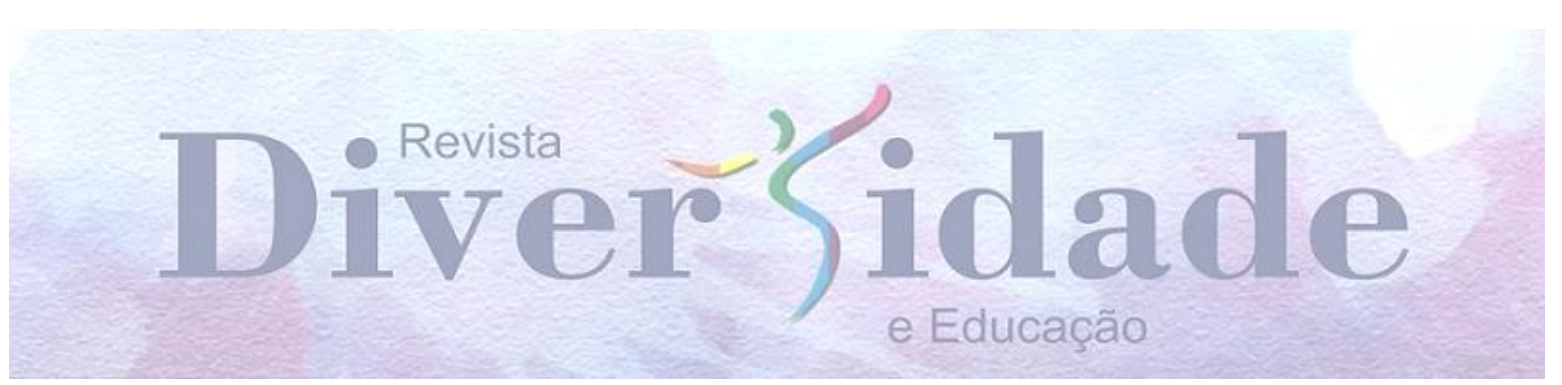

\title{
A UNIVERSIDADE E OS CORPOS INVISIBILIZADOS: PARA SE PENSAR O CORPO LGBT
}

\author{
UNIVERSIDAD Y CUERPOS INVISIBLES: PENSAR EL CUERPO LGBT
}

\section{UNIVERSITY AND INVISIBLE BODIES: TO THINK LGBT BODY}

\author{
Cristine Jaques Ribeiro ${ }^{1}$ \\ Camila de Freitas Moraes ${ }^{2}$ \\ Nino Rafael Medeiros Kruger ${ }^{3}$
}

\section{RESUMO}

O objetivo deste artigo é problematizar o lugar da população LGBT e, especialmente, da LGBTfobia enquanto manifestação de poder que violenta e subjuga corpos, evidenciando a negação do direito destes tanto na cidade, quanto no espaço universitário. Para tanto, será considerado, aqui, que os conceitos de disciplinarização e normatização do corpo são atitudes e modos de existência enquanto resultantes da construção social. Construção esta que merece ser denunciada frente as relações de poder. Ao fim, para a compreensão desta análise utilizou-se os entendimentos a partir de Michel Foucault, Judith Butler, Daniel Borrillo e Achille Mbembe.

PALAVRAS-CHAVES: Biopoder. Corpo LGBT. Universidade. Cidade

\section{RESUMEN}

El objetivo de este artículo es problematizar el lugar de la población LGBT y, especialmente, de LGBT como una manifestación de poder a la que los cuerpos violentos y subyugados, evidenciando la negación de su derecho en la ciudad, como en el espacio universitario. Por lo

${ }^{1}$ Doutora em Serviço Social. Universidade Católica de Pelotas (UCPEL), Pelotas, Rio Grande do Sul, Brasil.

2 Mestranda em Política Social e Direitos Humanos. Universidade Católica de Pelotas (UCPEL), Pelotas, Rio Grande do Sul, Brasil.

${ }^{3}$ Doutorando em Política Social e Direitos Humanos. Universidade Católica de Pelotas (UCPEL), Pelotas, Rio Grande do Sul, Brasil. 
tanto, se considerará aquí que los conceptos de disciplina y normatización del cuerpo, actitudes y modos de existencia como resultado de la construcción social. Es la construcción, que merece ser denunciada ante las relaciones de poder. Finalmente, para comprender este análisis, utilizamos la comprensión de Michel Foucault, Judith Butler, Daniel Borrillo y Achille Mbembe.

PALABRAS CLAVE: Biopoder; Cuerpo LGBT; Universidad; Ciudad.

\title{
ABSTRACT:
}

The objective of this article is to problematize the place of LGBT population and, especially of LGBT as a manifestation of power to which violent and subjugates bodies, evidencing the denial of their right in the city, as in the university space. Therefore, it will be considered here that the concepts of disciplinarization and normalization of the body, attitudes and modes of existence as a result of social construction. Construction is, which deserves to be denounced before the power relations. Finally, to understand this analysis we used the understanding from Michel Foucault, Judith Butler, Daniel Borrillo and Achille Mbembe.

KEYWORDS: Biopower; LGBT body; University; City.

\author{
$* * *$ \\ O corpo não é uma máquina como nos diz a ciência. Nem uma culpa como nos fez crer a \\ religião. O corpo é uma festa. \\ Eduardo Galeano
}

\section{Introdução}

O estudo aqui delineado tem como tema "O controle do Corpo LGBT na Universidade", apresentando como foco tratar as questões acerca da invisibilidade desses atores sociais que compõem a população LGBT no âmbito universitário. Esse é um problema social que tem tido um crescimento escalar no que diz respeito ao pensamento LGBTfóbico, legitimado por setores de considerável poder na sociedade, a saber: a política, a universidade, a medicina e os discursos religiosos pregnantes. Logo, é a partir da lógica foucaultiana que tais questões terão seus desdobramentos, sendo utilizada a noção de relação de poder e de disciplinarização dos corpos como eixo principal para se pensar e construir a temática. No entanto, antes se pretendeu problematizar o tema da cidade com a produção da subjetivação que nega as manifestações da diferença, impondo códigos de comportamentos determinados pela heteronormatividade.

Os principais questionamentos que orientaram este trabalho foram os seguintes: A universidade é um espaço cuja diversidade sexual tende a ser descaracterizada, marginalizada? Por outro lado, esse mesmo espaço, compreendido enquanto campo político, não poderia ser um lugar de inclusão e de combate à LGBTfobia? Quando provocamos tal pergunta, é no sentido de 
considerar também a importância das contribuições de Borrillo (2009), quando trata o tema da Homofobia enquanto construção social. No entanto, não se limita apenas a este, mas ousa a relação com o tema da LGBTfobia, pois a violência e discriminação produzida não se limita a um grupo específico, mas aos corpos que são controlados em seus modos de viver. Ainda, ressalta-se como o Ministério da Mulher, da Família e dos Direitos Humanos no Brasil trata com a especificidade do tema ${ }^{4}$. Portanto, quais são estratégias a serem usadas para facilitar o diálogo entre esses atores sociais que compõem a população LGBT e a universidade?

Inicialmente, realizou-se uma revisão de literatura a partir das contribuições foucaultianas sobre as noções de poder, corpo, sexualidade e gênero. Logo, através das análises de Michel Foucault, torna-se possível apresentar e compreender como as formas de resistência às imposições e aos padrões do silenciamento dos corpos, da sexualidade e do gênero podem fazerse presentes no campo social, sendo a Universidade um recorte desse lócus, onde os modos de existir possam ser (re) inventados e (re) pensados para além das normas impostas. O pensamento foucaultiano apresenta-se enquanto obra principal por se compreender que Foucault possibilitanos buscar tracejar por um caminho em que as práticas de liberdade possam se dar de maneira a recriar os modos de existir no campo social, sendo a Universidade um recorte deste, onde todas as formas de diversidade sexual possam fazer-se presentes, sem preconceitos e discriminações.

No que se segue, utilizou-se, também, sites eletrônicos com artigos que se relacionassem com a temática em comento. Sobre o objetivo deste trabalho, ressalta-se a importância de investigar se há na universidade espaços instituídos ou não, mas que debatam as questões da LGBTfobia com o intuito de reconhecer a voz dos agentes sociais, ou seja, de reconhecê-los e legitimá-los. Além disso, identificar se há discussões, a partir dos conceitos foucaultianos, sobre as questões dos dispositivos de poderes que tendem a tomar o corpo LGBT enquanto objeto de ser docilizado e normatizado. Por fim, a análise a ser feita aponta para a urgência de uma educação "outra", que inclui a própria universidade como um lugar de construção dessa nova política educativa sobre a LGBTfobia, bem como de implementação de políticas públicas focadas na diversidade sexual.

\section{Cidade espaço subjetivado}

A cidade, como espaço regulador e regulado, sugere problematização frente a sua formação. A cidade, construída socialmente e determinada pelas relações de saber e de poder,

4 Disponível: Violência LGBTfóbicas. https://www.mdh.gov.br/biblioteca/consultorias/violencialgbtfobicas-no-brasil-dados-da-violencia/view. Acesso em: 20/01/2020. 
condiciona-se, a partir de suas normas, comportamentos permitidos e desejados, por uma política que decide quem existe ou quem deixa de existir.

Os modos de singularizar a vida são dia a dia violentados por padrões de convivência impostos. Assim, espaços e lugares são resultantes da produção de subjetividade marcada pelo contexto que tenta invisibilizar os outros modos de ocupar o urbano.

A ordem capitalista produz os modos das relações humanas até em suas representações inconscientes: os modos como se trabalha, como se é ensinado, como se ama, como se trepa, como se fala, etc. (GUATTARI; ROLNIK, 2000, p. 42)

A cidade torna-se espaço de disputa das heterogêneas manifestações, portanto, pensar o corpo LGBT é questionar quem decide a circulação deste espaço. A rua, por exemplo, é de todos e para tanto deve ser ocupada, pois o corpo não é apenas o corpo - $\mathrm{CsO}$, com seus limites fronteiriços, mas o corpo sem órgãos, segundo Deleuze e Guattari (1996, p. 12):

Um CsO é feito de tal maneira que ele só pode ser ocupado, povoado por intensidades. Somente as intensidades passam e circulam. Mas o CsO não é uma cena, um lugar, nem mesmo um suporte onde aconteceria algo. Nada a ver com um fantasma, nada a interpretar.

A cidade heteronormativa impõe condicionamentos para convivência. O disciplinamento e o controle dos corpos acontecem como mecanismos de docilização das "condutas", das expressões, das práticas individuais em meio a uma geografia dominante. Consequentemente, a autorização da violência urbana contra os corpos LGBTS é socialmente aceita. Relações são individualizadas para que possam continuar invisibilizadas. Sanções são instigadas no sentido de impedir a expressão da diferença.

Os deslocamentos dos corpos LGBTS tornam-se uma necessidade de sobrevivência e de brecha na cidade. Deslocar para outro espaço, deslocar dos conceitos preestabelecidos, deslocar dos olhares punitivos. Os deslocamentos são práticas recorrentes para que os discursos eurocêntricos possam ao menos sofrer movimentos de desconstrução.

Numa sociedade como a nossa são bem conhecidos, é certo, procedimentos de exclusão. O mais evidente, o mais familiar também é o interdito. Sabe-se bem que não se tem o direito de dizer tudo, que não se pode falar de tudo em qualquer circunstância, que não é qualquer um, enfim, que pode falar de qualquer coisa. Tabu do objecto, ritual da circunstância, direito privilegiado ou exclusivo do sujeito que fala. [...] Notaria apenas que, nos nossos dias, as regiões onde a grelha é mais cerrada, onde as casas (...) se multiplicam, são as regiões da sexualidade e as da política. (FOUCAULT, [1971]1997, p. 4). 
A vida urbana sugere encontros e confrontos, sugere resistência e sobrevivência, para tanto é urgente reconhecer os movimentos "errantes" dos corpos que não se adéquam à normalização. Normalização fortalecida por discursos codificados a partir do estatuto de verdade sob e sobre. Consequentemente, concorda-se que a cidade constrói-se através de um pensamento único que, frente às heterogêneas manifestações e aos modos de viver, desfaz-se impulsivamente.

Através da naturalização do que é a cidade e para quem é a cidade, fronteiras entre público e privado vão se enraizando e questões tornam-se latentes, como: De quem é a rua e de quem é a casa ${ }^{5}$ ? Ou melhor, para quem é a rua e para quem é a casa? A permissão das manifestações, em cada lugar específico, desenvolve tipos de controle e de vigilância.

Políticas públicas que atendam às necessidades e garantam os direitos da população LGBT são brutalmente negadas. Assim, a cidade fecha-se em seus códigos de normalização, negando a existência de uma parcela de seus citadinos. Manter o segredo, como legitimação das normas de convivência, torna-se dispositivo de manutenção da biopolítica que regula a vida dos coletivos e de seus modos de habitar a cidade. A hierarquização dos espaços e das relações tem objetivo de manutenção da vigilância e da punição ${ }^{6}$.

A cidade torna-se o espaço que rejeita a diferença. Ocultar o desvio da norma resulta em exercício recorrente frente à moralidade instituída. A constituição de sistemas fechados de convivência sugere a proibição de manifestações marginais. A subjetivação captura modos de existir e "interioriza" fluxos capitalísticos, cujo objetivo é moldar subjetividades. Sendo assim, a cidade é produto privado de alguns para alguns, o restante obriga-se a ajustar-se.

O que caracteriza os modos de produção capitalístico é que eles não funcionam unicamente no registro dos valores de troca, valores que são da ordem do capital, das semióticas monetárias ou dos modos de financiamento. Eles funcionam também através de um modo de controle da subjetivação [...]. (GUATTARI; ROLNIK, 2000, p. 16).

No entanto, mesmo com as formas de subjetivação em marcha, instiga-se reconhecer as potências coletivas que denunciam os modelos da política com direção regulatória. Ao contrário da homogeneidade e do consenso, reconhece-se a heterogeneidade e o conflito. Heterogeneidade necessária para que processos revolucionários possam germinar e transformar espaços, relações e políticas. Para tanto, considera-se outra via, outros discursos, outros modos de conviver e de

${ }^{5} \mathrm{O}$ modelo de casa é construído a partir do modelo de casa burguesa, onde são estabelecidos os cômodos com suas subdivisões. Lugares permitidos para convivência grupal e individual. Lugares individualizados com suas funções específicas. (FOUCAULT, [1975]2004).

6 "Foucault demonstra em Vigiar e punir como a execução do presumido regicida Damiens durou horas, sobretudo para a satisfação da multidão" (MBEMBE, 2019, P. 22). Mecanismos de punição pública consentida pela sociedade, que em tempos atuais é realizada com outros artifícios, mas com mesmo fim. 
existir que não se enquadram, que não representam, que rompem com o discurso dominante. Discurso que defende o convívio "civilizado" que, em outras palavras, sustenta o imaginário masculino, hétero e branco.

Sendo assim, a cidade contém movimentos territorializados e territorializantes, compondo concomitantes processos de desconstrução, e nesse ínterim as ocupações do espaço vão sendo desenhadas. Alternativas surgem no cotidiano que solidificam resistências capazes de sacudir a valoração moral. O corpo LGBT na cidade é a denúncia das formas instituídas que pretendem controlar a vida em todas suas dimensões. É a denúncia das representações e das identidades paradigmáticas que impedem o fluir das linhas intempestivas.

Pensar a cidade a partir da realidade da população LGBT é problematizar como o direito à cidade constitui-se na arquitetura das relações. As questões que pulsionam a LGBTfobia são evidenciadas pelo Estado? Quais são as políticas públicas de combate à violência e à criminalização deste grupo no espaço urbano? A mobilidade torna-se privilégio para heterossexuais? Como a população LGBT circula, trabalha, diverte-se? A mobilidade da população LGBT ocorre nas mesmas condições de participação e de convivência frente aos outros citadinos? São muitos questionamentos que constroem este trabalho, cujo objetivo é defender a importância deste tema na construção da cidade e na negação de um pensamento único.

Se durante largo período o debate acerca da questão urbana remetia, entre outros, a temas como crescimento desordenado, reprodução da força de trabalho, equipamentos de consumo coletivo, movimentos sociais urbanos, racionalização do uso do solo, a nova questão urbana teria, agora, como nexo central a problemática da competitividade urbana. (ARANTES; VAINER; MARICATO, 2013, p. 76).

Portanto, a cidade é o resultado das produções coletivas, das forças que a movimentam, dos investimentos de uma política que deseja determinar quem vive ou quem morre. Desconstruir a ideia de um modelo único de cidade e, consequentemente, de um modelo de sexualidade que rege as relações afetivas é um modo de resistência frente à semiotização capitalista.

Com as problematizações postas, afirma-se que o corpo LGBT é corpo da cidade e, sendo a cidade produzida pelas relações de saber e poder, se reconhece que diversos espaços que a desenham tornam-se ambientes de disputa e de denúncia das formas arbitrárias de mortificar modos de existir. Sendo assim, a Universidade apresenta-se como um desses espaços que reproduzem o controle através da tentativa de tornar invisível a população "infame”. 


\section{A Sexualidade e Corpo}

Historicamente a sexualidade humana sempre foi pauta de interesses e problematizações por parte da ciência, e não obstante, na contemporaneidade, ainda é palco de grandes discussões, especialmente no campo da pesquisa social. A saber, as questões do feminino e do masculino e, consequentemente, da diversidade sexual sempre estiveram atreladas ao conjunto de regras e normativas sociais que se presentificam pela via das instituições jurídicas, educacionais, religiosas, pedagógicas, psicológicas e médicas (FOUCAULT, [1984]1999).

Sobre a questão da sexualidade, Foucault ([1984]1999) nos faz pensar que o poder presentificado em tais instituições inscreve-se na produção de um dado saber sobre a sexualidade humana. Saber este, que no campo social mantém-se a partir das relações de poder, sendo essas personificadas pela via dos discursos ou de ações, que tendem a colocar a sexualidade humana em duas categorias: a de normalidade versus anormalidade, assim como aceitável versus não aceitável. Isto é, o autor chama-nos atenção sobre a hierarquização sexual no transcorrer da história, afirmando, assim, que tal hierarquização sempre sobreveio de valores morais, religiosos, jurídicos e culturais da sociedade.

Sobre a sexualidade, Freud ([1905]1996) desvincula-a da procriação, assim como do modelo cristão-cultural vigente. Nesse período, a sexualidade sai da seara privada do casamento e da procriação, para o público, especialmente nos consultórios privados, onde as mulheres, as ditas histéricas, eram tratadas. Deste modo, Freud, ([1905]1996) ao ressignificar a questão da sexualidade, afasta, também, a noção de genitalidade, de maneira a aproximá-la de algo mais amplo, como qualquer forma de obtenção ou busca pelo prazer. Uma vez que o corpo humano estaria para além do campo biológico, este corpo humano também é um corpo psíquico e passível de sexualidade num todo, e não apenas em suas particularidades, como pênis e vagina.

Já para Bourdieu (1999), a questão da sexualidade inscreve-se numa relação de dominação, cabendo ao sexo masculino a dominação erotizada do feminino e ao sexo feminino, configurar-se no objeto erótico a ser dominado.

Lauretis (1987), por sua vez, compreende a sexualidade a partir das relações sociais, ou seja, manifesta-se e é produzida a partir das relações em sociedade. Assim, a sexualidade é entendida como posterior ao ser humano biológico, uma vez que o fato de nascer com um pênis ou com uma vagina não necessariamente determinaria a sexualidade do sujeito.

Por conseguinte, no que tange à LGBTfobia, que se desvela pelo ódio à sexualidade contrária à heteronormatividade, frente a sua gravidade, poderia ser comparada à xenofobia, ao racismo e também ao antissemitismo, segundo menciona Borrillo (2016, p. 13-14): 
Do mesmo modo que a xenofobia, o racismo ou o antissemitismo, a homofobia é uma manifestação arbitrária que consiste em designar o outro como contrário, inferior ou anormal; por sua diferença irredutível, ele é posicionado à distância, fora do universo comum dos humanos. Crime abominável, amor vergonhoso, gosto depravado, costume infame, paixão ignominiosa, pecado contra a natureza, vício de Sodoma - outras tantas designações que, durante vários séculos, serviram para qualificar o desejo e as relações sexuais ou afetivas entre pessoas do mesmo sexo. Confinado no papel do marginal ou excêntrico, o homossexual é apontado pela norma social como bizarro, estranho ou extravagante. [...] Â semelhança do negro, do judeu ou de qualquer estrangeiro, o homossexual é sempre o outro, o diferente, aquele com quem é impensável qualquer identificação.

Por sua vez, Carvalho e Duarte (2017) referem-se acerca da cultura homofóbica, da seguinte forma:

No plano da violência simbólica, os discursos científicos acabam se entrelaçando com as teorias do cotidiano (everyday theories) e formando uma espécie de senso comum (teórico) homofóbico que consolida de forma violenta a heteronormatividade. Não por outra razão, um olhar relativamente cuidadoso permite perceber que a homossexualidade foi historicamente posta à margem e em oposição aos padrões da cultura. Nesse aspecto, é possível perceber nas ciências modernas um continuum daquela forma mentis inquisitorial de identificação do desvio sexual e designação da homossexualidade como um pecado (p. 209).

Dito isso, Berger (1986) e Butler (2005) fazem referência aos vários mecanismos usados por uma dada sociedade para ajustar/ adaptar e/ou enquadrar os sujeitos indesejados. Para o autor, "o meio supremo e, sem dúvida, o mais antigo de controle social é a violência" (BERGER, 1986, p. 81).

Dentro desta temática, Mbembe (2019), em consonância com Berger (1986), vai mais além, ao trazer a noção de necropolítica, que se apresenta frente às opressões estruturantes de uma dada sociedade e que se dá pela abordagem do poder estatal - o qual através de sua soberania define aqueles que devam viver ou morrer. Isto é, refere-se à noção de poder que tende a determinar quem poderá viver e quem deverá morrer no seio social. Nessa lógica opera-se pela via do extermínio dos grupos que não têm lugar algum no sistema. Sendo assim, o autor chamanos atenção para uma política que parte da exclusão e/ou afastamento para uma política do extermínio.

Nesse sentido, acerca da sobrevivência e existência da comunidade LGBT e tendo como paralelo os efeitos normalizadores e disciplinares que atravessam o seio sociopolítico e que tendem a funcionar como base para a construção do anormal, Artaud (1983, p. 153) assinala que: 
"para existir basta abandonar-se ao ser, mas para viver é preciso ser alguém, e para ser alguém é preciso ter um osso, é preciso não ter medo de mostrar o osso e arriscar-se a perder a carne". Contudo, o autor nos ensina sobre intermináveis direitos de existir, quase sempre violados frente ao poder disciplinar que regula a noção dual de indivíduos normais e patológicos.

Ainda trazendo grandes contribuições, Chauí (1985), em consonância com o pensamento foucaultiano, entende a sexualidade como um conjunto de normas, valores morais e regras construídas historicamente ao longo da cultura. Além disso, a autora afirma que a repressão sexual, por sua vez, também pode ser compreendida pela mesma lógica. Isto é, como um conjunto de regras e interdições que tendem a controlar a manifestação da sexualidade, sobretudo, daqueles que estão na contramão do aceitável, da normalidade - fora das regras. Valores esses que acabam por corroborar com a exclusão, a marginalização e a estigmatização das Lésbicas, Gays, Bissexuais, Travestis e Transexuais - LGBT's.

Contudo, o que se pode observar é que apesar de muitas mudanças no cenário social, jurídico e político, ainda se fazem presentes, em nossa contemporaneidade, discursos condenatórios referentes à população LGBT, que buscam privá-los da estrutura social. Desta forma, a população LGBT ainda é associada aos conceitos de pecado, asco, vergonha, imoralidade, degeneração e patologia. A sexualidade humana é vista como uma forma de controle social, que tem como fim maior a regulação dos corpos, que prioriza o binômio da normalidade e da anormalidade. Esta, sendo o lugar dado a população LGBT, um lugar de opressão e intolerância. São meios de expressão do controle social acerca dos corpos, de um poder normativo e disciplinador, tal qual Foucault ([1975]2004) nos fala em seu livro Vigiar e Punir. O autor traz questões do corpo como algo a ser dominado e submetido ao poder regulador do Estado, da Sociedade e da Política.

Pode-se inferir que a partir do pensamento de Foucault ([1975]2004) a população LGBT, frente à sexualidade e sua relação com o prazer, tende a ser controlada, por estar em dissonância com as regras sociais, morais e religiosas, principalmente as que condizem com a noção de procriação e as relações monogâmicas heterossexuais. Isso, pois a homossexualidade, a bissexualidade e a transexualidade não desempenhariam o papel principal da procriação, visto que estariam apenas envoltos pelo prazer. Desse modo, justificar-se-ia excluí-los e subjugá-los, deixá-los à margem.

Como nas palavras de Foucault ([1984]1999, p. 11-12): “o discurso sobre a repressão mantém-se porque é fácil de ser sustentado e corrobora com o poder". Isso significa que o poder tende a ser percebido e/ou observado como um exercício, ou seja, o poder pode vir a ser chamado de governo num sentido mais amplo, pois este governo é, e está, presente, sobretudo, 
na relação entre os indivíduos/sujeitos. Nesse sentido, o poder sobre o Corpo LGBT é algo a ser disciplinado, investigado, estudado e normalizado. É, então, a partir da regulamentação dos corpos, que se dá início à formação de modelos ideais e aceitos socialmente, estando, estando nesse contexto de formação, a população LGBT excluída.

\section{Entrelaçamentos entre a Universidade e a Comunidade LGBT}

Utopicamente, Santomé (2002) e Borrillo (2009) trazem em seus discursos princípios ideológicos acerca daquilo que viria ser a Universidade. Conceito que nos faz refletir sobre o lugar e o papel da formação do discente nesse contexto. Caberia à Universidade garantir e ajudar na formação de seus estudantes sobre o respeito tanto a sua identidade, quanto a de outrem, bem como, o respeito à singularidade de cada sujeito, especialmente, no que condiz à sexualidade.

Nesse sentido, uma das funções da Universidade dar-se-ia na direção de assegurar seus estudantes em relação a todo e qualquer ato que venha a discriminá-los no que diz respeito à diversidade, seja esta étnico-racial, financeira, sexual, entre outras. Aqui, neste primeiro momento, refiro-me justamente à diversidade em seu sentido amplo, como um grupo e/ou conjunto de diferenças e valores compartilhados pelos seres humanos no âmbito social (BORRILLO, 2009).

Como é sabido, com o processo de democratização do ensino superior no Brasil, através de políticas que ampliaram o acesso à Universidade, possibilitou-se uma diversidade de discentes nesse cenário. Isto é, alunos pretos, pardos, afrodescendentes, indígenas, vulneráveis economicamente e alunos da rede pública de ensino, por exemplo, tiveram acesso à Universidade. Entretanto, o fato destes terem acesso à Universidade não thes deu garantias de permanência. Tais estudantes, com perfis divergentes daqueles que, social e historicamente, são tidos enquanto ideais e naturais no âmbito universitário, brancos, heterossexuais e com poder aquisitivo elevado, em comparação aos que se encontram divergentes desse modelo ideal, acabaram por encontrar nesse cenário acadêmico a atualização das desigualdades sociais e hierarquias de gênero, raça e sexualidade. Desigualdades essas já enfrentadas em seu cotidiano e reimpressas/reproduzidas no cenário universitário. Sendo assim, pode-se pensar, então, que a universidade, aqui compreendida enquanto instituição social e política, possui suas regras, valores, hierarquias e corpo social (alunos, professores, funcionários e comunidade) e tem sido palco de reproduções de opressões, violências e privilégios (SANTOS; CHAUÍ, 2013).

Por conseguinte, pensar a Universidade como um espaço de mudança sociocultural e política é estar ciente de que este também é um local onde grupos sociais e suas particularidades são inscritos através de relações de poder. A moralidade e a sexualidade são colocadas nos 
discursos e nos comportamentos de julgamento e de pré-conceitos que se presentificam nas relações humanas. Logo, pensar a comunidade LGBT é estar ciente de que esta tende a ser posta em uma categoria de uma humanidade menor, de não-sujeitos, como bem nos explica Foucault ([1972]1978) na História da Loucura, em que a condição atribuída aos loucos era a de serem supliciados, excluídos, curados e, posteriormente, disciplinados.

Buscando uma transposição dessas ideias, considero que os outrora chamados loucos eram vistos como seres abjetais por transgredirem a ordem normativa da época. Da mesma forma, pode ser pensado atualmente, tendo como referência a comunidade LGBT, que, obedecendo a essa lógica, precisa ser curada e normatizada por justamente estar fora dos padrões sociais aceitáveis (FOUCAULT, [1972]1978).

Perante isso, é preciso compreender que a normatização, enquanto imposição de um padrão social, moral, comportamental e ético, é construída e historicamente naturalizada como normal. Nesse sentido, todo o comportamento que transcende às configurações heteronormativas é algo que deva ser disciplinado. Qualquer sujeito que não se identifique pertencente às configurações padronizadas socialmente, passa a ser visto como um sujeito excluso e passível de violência e discriminações. Assim, é a partir da regulamentação do modelo ideal que se dá a existência de preconceitos que podem funcionar como barreiras no contexto universitário (FOUCAULT, [1972]1978).

Acredita-se, então, que a Universidade venha a ser um lugar privilegiado de exercício de discursos pautados em relações sociais, por constituir-se como um palco tanto de reprodução, quanto de debate das hierarquias, e é preciso perceber como isto ocorre, para tornar efetivo o combate às desigualdades. Como bem confirma Scott, Lewis e Quadros (2009, p. 15):

[...] O discurso institucional, o material didático, bem como as relações professor-aluno e as estabelecidas entre os grupos de pares apresentam-se como lócus de atualizações da sociedade mais ampla, apontando para a necessidade de percebermos a escola como um importante lugar que oferece a sua própria configuração de relações de poder. É neste sentido que o lugar privilegiado para repensar essas hierarquias, é no diálogo com as reflexões e interpretações das experiências trazidas por professores, bem como uma conscientização de suas várias formas de expressão e implicações para os grupos situados em posições diversas, frequentemente marginais, não somente na escola, mas também fora dela.

Seguindo o pensamento de Scott, Lewis e Quadros (2009), mas tendo como referência o contexto universitário, o exercício de pensar a LGBTfobia, que tem como manifestações o preconceito, a violência e a discriminação contra a comunidade LGBT no âmbito universitário, é estar atento para o fato de que historicamente a comunidade LGBT sofre preconceito e 
opressão/perseguição por sua orientação sexual e identidade de gênero, tanto em sua dimensão afetiva, quanto cultural. A primeira trata da não aceitação ou da rejeição às homossexualidades; a segunda diz respeito à intolerância a quaisquer ações políticas que venham a garantir direito e igualdade à comunidade LGBT.

No mais, a intolerância, ou seja, a LGBTfobia assemelha-se a outras condutas que são consideradas discriminatórias, de modo que a comunidade LGBT é vista, em diferentes contextos, como assujeitada, como seres exclusos de seus direitos e consequentemente de humanização (SCOTT; LEWIS; QUADROS, 2009).

Logo, todo aquele que está em contraposição às configurações sexuais heteronormativas estariam sujeitos à discriminação. Sendo assim, a LGBTfobia ultrapassaria as questões de relações interpessoais, vindo a ocupar espaços institucionais como escolas, universidades, igrejas, serviços de saúde, dentre outros (FOUCAULT, [1972]1978).

Ainda trazendo grandes contribuições, Borrillo (2009) afirma que a LGBTfobia é um controle de gênero através do qual a heteronormatividade atuaria como um dispositivo da adequação social. O autor chama atenção ao fato de que há uma relação de biopoder que se expressa no social de maneira a sistematizar e controlar, inclusive a sexualidade de outrem (BORRILO, 2009).

Partindo desse pressuposto, supõe-se que a comunidade LGBT, frente ao sentimento de pertença, participação e convivência social na Universidade, é de suma relevância na produção científica, em especial, para que se possa haver temas em defesa dos interesses dessa comunidade. Além disso, é importante para a construção de políticas públicas que pretendam desconstruir acerca da discriminação e do preconceito institucional, de modo a contribuir com a redução das desigualdades e da vulnerabilidade enfrentada pela comunidade LGBT nesse cenário. Acreditamos que é de fundamental relevância pensar e discutir tais questões na Universidade e tentar construir um lugar realmente voltado para o respeito da singularidade de cada estudante, mas, principalmente, construir, com isso, um lugar de coexistência com a diversidade sexual.

Desta forma, torna-se relevante que a Universidade venha a ser compreendida em sua prática como um local fundamental no processo de mudança sociocultural, por justamente ser um terreno frutífero para a construção de respeito e de equidade no que condiz a pluralidade e/ou diversidade.

Pautando-se nesses referenciais, estamos propondo, no âmbito da pesquisa científica, pensar o contexto universitário como um espaço de afirmação política e de constituição desses atores sociais, uma vez que a universidade, enquanto lugar de poder, pode ser parte do problema 
frente a LGBTfobia quando silencia estes corpos, quando discrimina ou prática a violência LGBTfóbica. Por outro lado, pode ser, também, parte da solução, quando estabelece discussões sobre a temática LGBT, a fim de se desconstruir as pressões e os preconceitos sociais diante das normatividades sexuais.

Por conseguinte, frente às poucas pesquisas encontradas, nota-se o quão necessário faz-se pensar essa temática e, mais que isso, remete à reflexão de que o espaço universitário, compreendido como um campo político, é de suma importância para se promover debates e pesquisas. Os atores sociais que compõem a comunidade LGBT participam de uma sociedade que tende a marginalizá-los e a exclui-los. O que tem, então, a Universidade a ver com isso?

Supõe-se, que a Universidade, enquanto instituição social com suas regras, valores e 'corpo social' (alunos, professores, funcionários e comunidade), por um lado, é um espaço cuja diversidade sexual pode vir a ser descaracterizada e marginalizada. Por outro, também é um espaço que, inclusive pela sua função educativa e de convivência, pode vir a recriar o sentimento de pertença e de inclusão daqueles que se sentem estigmatizados (DE ASSIS CÉSAR; DUARTE; SIERRA, 2013).

Considerando as questões apontadas acima, a Universidade e a rede que a compõe devem ter um papel fundante na promoção e no respeito à diversidade por meio do diálogo acerca das políticas públicas de combate à discriminação, especialmente por motivo de orientação sexual, gênero, etnia, religião, situação econômica e etc (DE ASSIS CÉSAR; DUARTE; SIERRA, 2013).

Nesse ínterim faz-se necessário pensar/repensar as manifestações da diversidade sexual em distintos campos discursivos, em especial, na Universidade, cujo contexto é de um espaço da constituição do sujeito a partir de diferentes formas de convivência e participação.

\section{Conclusão}

Este artigo apresentou um breve fragmento da obra de Foucault e seus comentadores, atendo-se principalmente ao que se refere às relações de poder frente à uma sociedade disciplinar e normatizada, que subjuga, exclui e põe à margem quaisquer indivíduos que estão na contramão daquilo que lhe é imposto, entre estes, a população LGBT, frente à imposição da heteronormatividade. Pode-se identificar, então, que o poder encontra-se por toda parte, pois este é fluido e se manifesta tanto pela família quanto pelo Estado, enquanto corporificação de tal poder. 
Logo, para se estabelecer um dado poder é preciso força ou coercitividade, sendo essa imposição de força sobre um dado corpo. Aqui se privilegia expor o corpo LGBT enquanto um corpo aferido pela via da assujeição e da subjugação, seja pela via da violência física, psicológica, moral ou verbal (calúnia ou difamação), ou até mesmo homicídio, em todo campo por onde o poder circula, desde os espaços universitários aos espaços e/ou territórios da cidade, promovendo, assim, a questão denominada LGBTfobia. Questão que precisa ser denunciada, discutida e debatida em todas as esferas pelas quais o poder circula, uma vez que é somente por essa via que outras formas de existência podem ser reconhecidas, respeitadas e passíveis de existirem em sua diversidade.

Por fim, relacionar os temas da cidade com universidade para problematizar a questão da LGBTfobia é ousar a publicizar os discursos que se constroem nos espaços institucionalizados. Espaços que ora são atravessados por normatizações, que moralizam modos de existência como também possibilidades transversalizantes, que se impõem frente às práticas construídas coletivamente dos corpos que resistem à heteronormatividade. Assim, as últimas questões que ficam em aberto são: O que é cidade e universidade? De quem é a cidade e a universidade? Para quem é?

\section{Referências}

ARANTES, O.; VAINER, C.; MARICATO, E. A cidade do pensamento único: Desmanchando consensos. 8. ed. Petrópolis: Vozes, 2013. 192 p.

ARTAUD, A. Para acabar com o julgamento de Deus. In: WILLER, C. (Org.). Escritos de Antonin Artaud. Porto Alegre: LP\&M, 1983, p. 145-162.

BORRILLO, D. A homofobia. In: LIONÇO, T.; DINIZ, D. Homofobia e educação: um desafio ao silêncio. Brasília: Editora UnB, 2009, p. 15-46.

. Homofobia: história e crítica de um preconceito. Tradução de Guilherme João de Freitas Teixeira. 1. ed. 3. reimp. Belo Horizonte: Autêntica Editora, 2016. 144 p.

BERGER, P. Perspectivas sociológicas. Petrópolis: Vozes, 1986. 202 p.

BOURDIEU, P. A dominação masculina. Tradução Maria Helena Kuhner. Rio de Janeiro: Bertrand Brasil, 1999. 160 p. 
BUTLER, J. Corpos que importam: sobre os limites materiais e discursivos do sexo. Buenos Aires: Paidos, 2005. 400 p.

CARVALHO, S. de; DUARTE, E. P. Criminologia do preconceito: racismo e homofobia nas ciências criminais. São Paulo: Saraiva, 2017. 262 p.

CHAUÍ, M. Repressão sexual: essa nossa (dês) conhecida. São Paulo: Brasiliense, 1985. 211 p.

DE ASSIS CÉSAR, M. R.; DUARTE, A.; SIERRA, J. C. Governamentalização do Estado, movimentos LGBT e escola: capturas e resistências. Educação, v. 36, n. 2, p. 192-200, 2013. Disponível em: <http://www.redalyc.org/articulo.oa?id=84827901007>. Acesso em: 08 mar. 2019.

DELEUZE G, GUATTARI F. Mil platôs: capitalismo e esquizofrenia. V. 3. São Paulo: Editora 34, 1996. $715 \mathrm{p}$.

FREUD, S. (1905). Três ensaios sobre a teoria da sexualidade. In: Um caso de Histeria, Três Ensaios Sobre a Sexualidade e outros Trabalhos (1901-1095). Rio de Janeiro: Imago, 1996, p. 119-209. (Edição standart brasileira das obas psicológicas completas de Sigmund Freud, 7).

FOUCAULT, M. (1971). A Ordem do Discurso: aula inaugural no Collége de France pronunciada em 02 de dezembro de 1970. Tradução Laura Fraga de Almeida Sampaio revista por Nuno Nabais. Lisboa: Relógio D’água Editores, 1997. 80 p.

FOUCAULT, M. (1972). História da Loucura na Idade Clássica. Tradução José Teixeira Coelho Netto. São Paulo: Editora Perspectiva, 1978. 608 p. (Coleção Estudos).

FOUCAULT, M. (1975). Vigiar e Punir: Nascimento da Prisão. Tradução Raquel Ramalhete. Petrópolis: Editora Vozes, 2004. 296 p.

FOUCAULT, M. (1984). Em defesa da sociedade: curso no College de France (1975-1976). Tradução Maria Ermantina Galvão. São Paulo: Martins Fontes, 1999. 382 p. (Coleção Tópicos).

GUATTARI, F.; ROLNIK, S. Micropolítica: Cartografias do Desejo. 6. ed. Rio de Janeiro: Vozes, 2000. 327 p.

LAURETIS, T. A tecnologia do gênero. 1987. Disponível em: <http://marcoaureliosc. com.br/cineantropo/lauretis.pdf>. Acesso em: 15 jan. 2019. 
MBEMBE, A. Necropolitica: seguido de sobre el gobierno privado indirecto. Traducción y Edición Elisabeth Falomir Archambault. Santa Cruz de Tenerife: Melusina, 2019. 120 p. SANTOMÉ, J. T. As culturas negadas e silenciadas no currículo. In: SILVA, T. (Org.).

Alienígenas na sala de aula. Petrópolis: Vozes, 2002, p. 159-177. (Coleção estudos culturais em educação).

SANTOS, B. de S.; CHAUÍ, M. Direitos humanos, democracia e desenvolvimento. 1. ed. São Paulo: Cortez, 2013. 136 p.

SCOTT, P.; LEWIS, L.; QUADROS, M. T. de. Gênero, diversidade e desigualdades na Educação: interpretações e reflexões para a formação docente. Recife: Editora Universitária UFPE, 2009. 200 p.

Recebido em outubro de 2019. Aprovado em dezembro de 2019. 